\title{
Córnea plana congênita: relato de caso e revisão de literatura
}

\section{Congenital cornea plana: case report}

\author{
Vera L. D. M. Mascaro ${ }^{(1)}$ \\ Lênio S. Alvarengáa ${ }^{(2)}$ \\ Juliana M. Ferraz Sallum ${ }^{(3)}$ \\ Denise de Freitas ${ }^{(4)}$
}

Departamento de Oftalmologia da Universidade Federal de São Paulo/ Escola Paulista de Medicina.

(1) Encarregada do setor de Doenças Externas Oculares de Córnea, Hospital do Servidor Público EstadualFMO, Chefe de ambulatório, Setor de Doenças Externas Oculares e Córnea, Departamento de Oftalmologia, UNIFESP - EPM.

(2) Residente do $3^{\circ}$ ano, Departamento de Oftalmologia, UNIFESP- EPM.

(3) Pós-graduanda, Departamento de Oftalmologia, UNIFESP-EPM

(4) Chefe do Setor de Doenças Externas Oculares e Córnea, Departamento de Oftalmologia, UNIFESP- EPM.

Endereço para correspondência: Vera Lucia D. M. Mascaro. Av. Paulista, 807 Cj. 1024. São Paulo (SP). CEP 01311-100.Tel283-4200.e-mail:vmascaro@unisys.com.br

\begin{tabular}{|l|}
\hline \multicolumn{1}{|c|}{ RESUMO } \\
\hline Objetivo: Descrever os casos de dois irmãos com diagnóstico de \\
córnea plana congênita bilateral e alta hipermetropia, uma vez que \\
não temos, no Brasil, conhecimento de referências anteriores sobre \\
famílias afetadas por tal entidade. \\
Relato dos casos: Dois irmãos com grave aplanamento corneal, \\
“esclerização" limbar, opacidade estromal central, achatamento da \\
câmara anterior, elevada hipermetropia e pseudo-ptose. \\
Discussão: Córnea plana congênita é uma entidade extremamente \\
rara, caracterizada pelo achatamento anormal da curvatura corneal. \\
Discute-se os possíveis tipos de herança, uma vez que cada um produz \\
apresentação clínica característica desta entidade que, neste caso, ao \\
lado da distribuição familiar, corrobora com o diagnóstico de córnea \\
plana congênita com herança autossômica recessiva. Chama-se a \\
atenção para o erro de refração e prevenção do glaucoma, cuja inci- \\
dência está aumentada nestes casos.
\end{tabular}

Palavras-chave: Anomalia corneal congênita; Córnea plana; Esclerocórnea; Hipermetropia

\section{INTRODUÇÃO}

Córnea plana é uma malformação córneo-escleral hereditária, congênita, extremamente rara que foi inicialmente descrita por Rubel em 1912, caracterizada pelo achatamento anormal da curvatura da córnea ${ }^{1,2}$. As curvaturas da córnea e esclera são aproximadamente iguais e em alguns casos a córnea é até mais plana do que a esclera. É vista, freqüentemente, em associação com esclerocórnea e pode vir associada a microcórnea, embriotoxon posterior, catarata congênita, coloboma anterior e posterior e aplasia macular. A esclerocórnea, nestes casos, é periférica produzindo uma pseudomicrocórnea provocada pela indefinição do limbo, o qual é tipicamente bem definido na microcórnea simples ${ }^{1-3}$.

Os dados em relação ao diâmetro corneal, em caso de córnea plana, mostram uma grande variedade, pois nem sempre fica claro se a medida trata do diâmetro total ou só do diâmetro da parte transparente da córnea. A observação de que todos os casos de córnea plana apresentam algum grau de "esclerização" periférica ou central levaram ao argumento de que a córnea plana e esclerocórnea são, de fato, a mesma entidade. O diagnóstico diferencial se faz pelo achatamento anômalo da córnea plana em contraste com a transparência anômala da esclerocórnea ${ }^{3-5}$.

Nos casos de córnea plana é comum encontrar opacidades estromais difusas, centrais, de aproximadamente $5 \mathrm{~mm}$ de largura. Estas opacidades ocorrem na maioria dos casos da forma recessiva, mas nunca aparecem nos 
casos com herança dominante. A câmara anterior pode ser estreita e a pálpebra ter aparência ptótica ${ }^{1,3-5}$.

Acredita-se que seja o resultado da parada do desenvolvimento no quarto mês de vida fetal, quando a curvatura corneal normalmente aumenta em relação à da esclera. $\mathrm{O}$ padrão de herança pode ser autossômico dominante ou recessivo ${ }^{3,4}$.

A baixa acuidade visual com alta hipermetropia é o erro refracional mais freqüente em casos como este. Entretanto, existem casos descritos com refrações variando entre $+17,5 \mathrm{D}$ até $-9,0 \mathrm{D}$, apesar da reduzida capacidade refracional da córnea, pois o comprimento axial do bulbo ocular e o cristalino podem variar ${ }^{1,6}$.

A câmara anterior pode ser rasa e é comum o aparecimento de glaucoma de ângulo estreito. O glaucoma de ângulo aberto também pode ocorrer ${ }^{3,4,7}$.

O objetivo deste trabalho é descrever os casos de dois irmãos com diagnóstico de córnea plana, já que não temos, no Brasil, referências anteriores sobre famílias afetadas por córnea plana congênita. Também chamamos a atenção para a correção óptica que deve, idealmente, ser instituída precocemente e, chamar a atenção para a prevenção de glaucoma, cuja incidência está aumentada nestes casos.

\section{RELATO DOS CASOS}

CBS, sexo masculino, 23 anos de idade, natural de Esplanada (BA) e procedente de São Paulo, referia uso de óculos com lentes de grau elevado desde os oito anos de idade e que sua visão nunca foi boa. Não apresentava alterações sistêmicas. Seus pais, não consangüíneos, e irmão mais novo não apresentavam alterações oftalmológicas. Referia uma irmã com alterações oculares semelhantes às suas. Negava outros casos semelhantes na família.

Ao exame oftalmológico, o paciente apresentava acuidade visual de 20/50 em ambos os olhos com a seguinte refração,

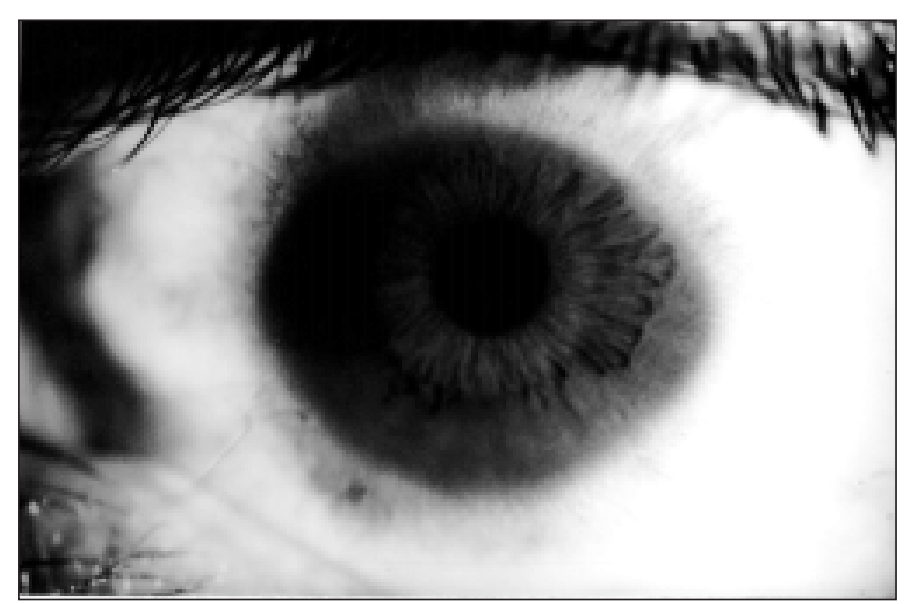

Fig. 1 - Fotografia à lâmpada de fenda. Observa-se a perda da precisão dos limites limbares, "esclerização", pior nas regiões inferior e superior dando à córnea a aparência elíptica. sob cicloplegia: OD: + 14,50 DE/ + 1,50 DC a $70^{\circ}$ e $\mathrm{OE}$ : $+13,00 \mathrm{DE} /+1,00 \mathrm{DC}$ a $110^{\circ}$.

Ao exame externo o paciente aparentava ser portador de leve blefaroptose. À lâmpada de fenda as córneas pareciam achatadas, ambos os olhos mostravam uma perda da precisão dos limites limbares ("esclerização"), pior nas regiões inferior e superior (Figura 1) que conferia à córnea uma aparência horizontalmente elíptica. A área transparente de córnea media, no OD: 8,0 x 9,0 mm e no OE: 7,0 $\mathrm{mm}$ x 9,0 $\mathrm{mm}(\mathrm{V} / \mathrm{H})$. As córneas, em seu centro, apresentavam, no estroma superficial e médio, discretíssima perda da transparência cercada por um halo mais transparente circundado pelo limbo mais opaco. Não foi notada vascularização. As câmaras anteriores de ambos os olhos eram estreitas. Pupila, íris, e segmento posterior apresentavam-se normais em ambos os olhos. A pressão intra-ocular e o fundo de olho eram normais em ambos os olhos. O exame sistêmico detalhado não revelou qualquer anormalidade.

A ceratometria, medida com ceratômetro Baush \& Lomb $^{\circledR}$, revelou miras irregulares e menores do que 30 dioptrias (D) em ambos os olhos; medida pelo topógrafo PAR ${ }^{\circledR}$ obtivemos curvaturas nos $3 \mathrm{~mm}$ centrais de 28,23 a $78^{\circ}$ e 23,79 a $168^{\circ}$ no olho direito e 28,94 a $102^{\circ}$ e 25,46 a $12^{\circ}$ no OE (Figura 2). A biomicroscopia ultra-sônica mediu a espessura central no OD, 469 micra e no OE, 480 micra, dentro da normalidade; mostrou ainda: invasão de tecido escleral na córnea periférica em $360^{\circ}$ em ambos os olhos, linha de alta refletividade estromal central disposta a 220 micra da superfície no OD e a 185 micra da superfície no OE, ângulo aberto nos $360^{\circ} \mathrm{em}$ ambos os olhos e câmara anterior com profundidade diminuída em relação aos padrões de normalidade, $1,73 \mathrm{~mm}$ em ambos os olhos. A biometria ocular realizada com ecobiômetro no modo A revelou comprimento axial de 20,01 mm no OD e 20,24 mm no OE. Todos esses dados foram confirmados pela biomicroscopia computadorizada do segmento anterior - EAS $1000^{\circledR}$ - que, além desses dados, informou sobre o valor do ângulo da câmara anterior, o qual no OD apresentava $20,71^{\circ} \mathrm{e}$ no $\mathrm{OE} 20,13^{\circ}$ (GRAU 2), raio de curvatura corneano de 12,39 $\mathrm{mm}$ no $\mathrm{OD}$ e $12,37 \mathrm{~mm}$ no OE e sobre as características do cristalino, como a densidade, que no caso era normal e espessura de 3,29 mm no OD e 3,28 mm no OE (Figura 3). Devido ao risco potencial de glaucoma por oclusão angular realizouse o teste de provocação em quarto escuro com inclinação cefálica, não sendo evidenciado aumento da pressão intraocular.

No exame, a irmã acometida apresentava as mesmas alterações descritas acima, porém com menor porção transparente das córneas (OD: 7,0 x 7,0 mm H/V e OE: 8,0 x 7,0 mm H/V). Apresentava acuidade visual de 20/60 no OD e 20/40 no OE com a seguinte refração: $\mathrm{OD}+16,00 \mathrm{DE}$ e $\mathrm{OE}+17,00 \mathrm{DE}$, sob cicloplegia. A pressão intra-ocular e o fundo de olho eram normais em ambos os olhos. A curvatura corneal medida com ceratômetro Baush \& Lomb $^{\circledR}$ mostrou-se menor do que 30,00 $\mathrm{D}$ em ambos os olhos. A medida exata, por meio do topógrafo computadorizado, não foi conseguida. 


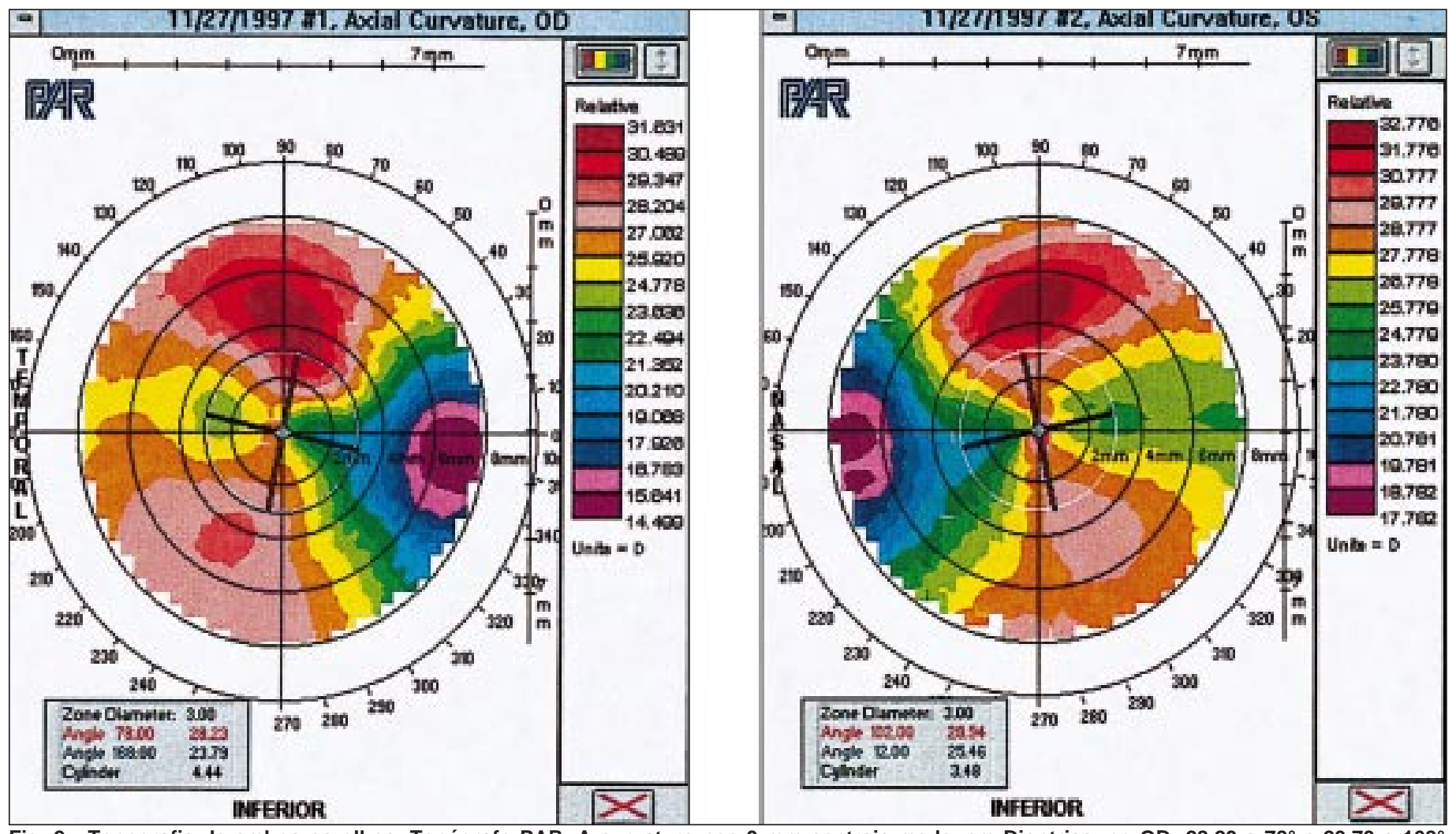

Fig. 2 - Topografia de ambos os olhos. Topógrafo PAR. A curvatura nos $3 \mathrm{~mm}$ centrais mede, em Dioptrias, no OD: 28,23 a $78^{\circ}$ e 23,79 a $168^{\circ}$ e no

OE: 28,94 a $102^{\circ}$ e 25,46 a $12^{\circ}$.

\section{DISCUSSÃO}

A córnea, para ser considerada plana, deve ter uma curvatura menor do que 43,00 dioptrias (D), mas medidas de 25 a 35 dioptrias são mais comuns. Leituras como 23,00 D têm sido reportadas na literatura ${ }^{5,6}$.

A patogênese do aplanamento anormal da córnea, até hoje, não é conhecida. Trata-se de uma malformação com expressividade variável ${ }^{6}$. Existem pelo menos duas formas genética e clinicamente distintas de córnea plana. A primeira forma, CNA1 (Cornea plana 1; MIM n ${ }^{\circ} 121400$ ) é mais leve (curvatura corneana com valor médio de $37,8 \pm 1,6 \mathrm{D}$ ), apresenta herança autossômica dominante. A segunda forma, CNA2 (Cornea plana 2; MIM n ${ }^{\circ}$ 217300), mais grave (curvatura corneana com valor médio de $29,9 \pm 5,1 \mathrm{D})$, decorre de herança autossômica recessiva ${ }^{8}$.

A CNA1 foi mapeada no cromossomo $12 \mathrm{q}$ numa região entre os marcadores D12S82 e D12S51 que é a mesma região para a qual a forma recessiva da córnea plana, CNA2, foi assinalada em famílias finlandesas, numa região crítica a apenas 0,04-0,3 cM (Centi Morgan) do marcador D12S351. Foram descritas outras famílias com a forma autossômica dominante da córnea plana que não foram mapeadas para o cromossomo 12q, não se podendo descartar, nestas famílias, sequer a herança mitocondrial ou ligada ao "X". Isto é indício de que deva existir, pelo menos, três apresentações da doença com duas formas dominantes distintas ${ }^{6-8}$.

Resta ainda ser determinado se a córnea plana recessiva e dominante são causadas por mutações diferentes de um único gene ou se na região do braço longo do cromossomo 12 a mutação de dois ou mais genes são responsáveis pela anomalia ${ }^{6,8}$.

As alterações clínicas dos pacientes aqui descritos: achatamento corneano, "esclerização" límbica, opacidade estromal central, forma horizontalmente oval da córnea, câmara anterior rasa, elevada hipermetropia e pseudo-ptose concordam com todos os achados clínicos descritos nesta entidade. A severidade do aplanamento destas córneas com raio de curvatura de $12,39 \mathrm{~mm}$ no OD e $12,37 \mathrm{~mm}$ no OE e o fato de serem dois afetados numa mesma irmandade com pais normais levaram-nos à conclusão que o diagnóstico do padrão de herança é autossômica recessiva. Neste caso, pode-se suspeitar de consangüinidade presumida quando se leva em conta a procedência dos pais da mesma e pequena cidade.

O comprimento axial neste paciente era no OD de 20,01 $\mathrm{mm}$ e no OE de 20,24 $\mathrm{mm}$ o que é considerado menor do que a média normal $(24 \mathrm{~mm})$ porém, não é suficientemente pequeno para configurar microftalmia ou nanoftalmia em que o comprimento axial varia de 16 a $18,5 \mathrm{~mm}^{3,9}$.

Este paciente apresentava dois fortes motivos para a elevada hipermetropia, achatamento corneal e comprimento antero-posterior diminuído. Os problemas ópticos não podem 


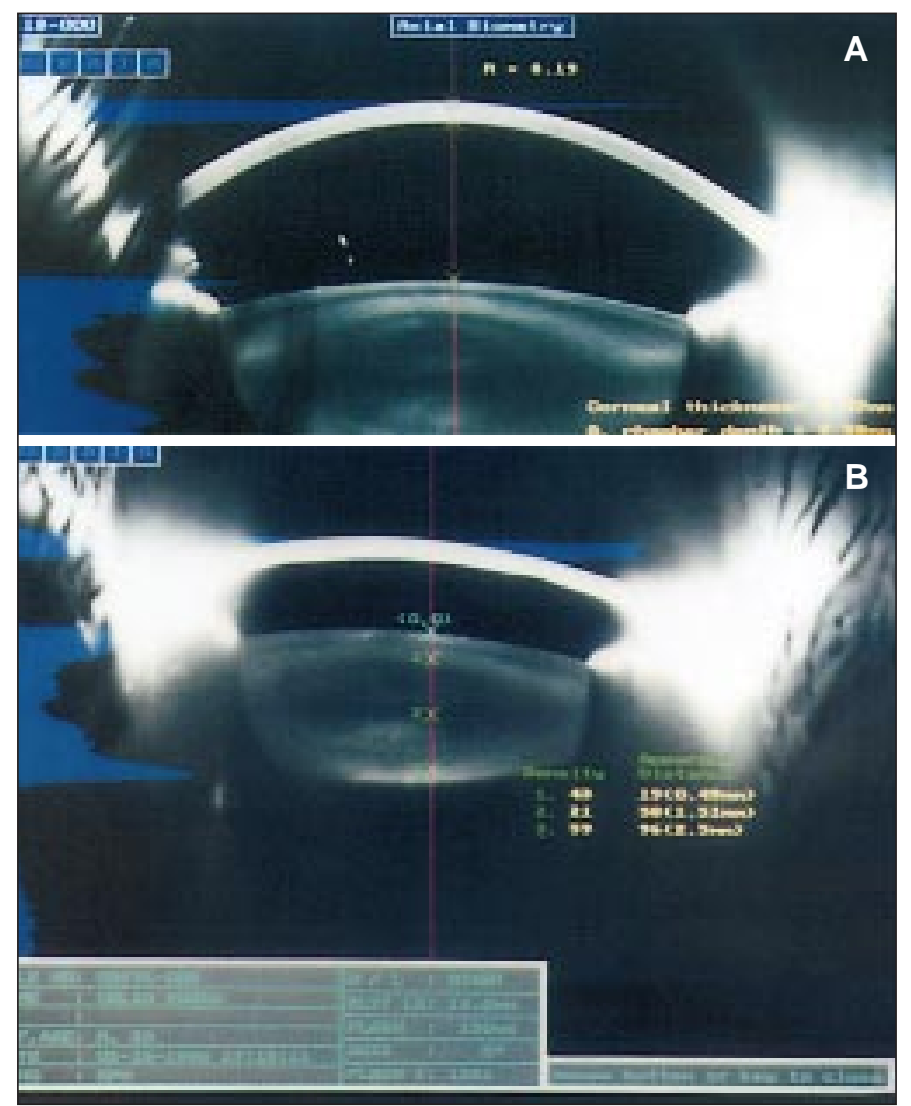

Fig. 3 - Biometria Computadorizada do Segmento anterior - EAS 1000: A - Segmento anterior de um olho normal; B - Córnea plana: Ângulo da câmara anterior: 20,71 no OD e 20, 13 no OE. Raio de curvatura corneal: OD - 12,39 mm e OE - 12,37 mm.

ser completamente resolvidos com o uso de óculos devido aos defeitos ópticos das lentes para alta hipermetropia ${ }^{10}$, ou por lentes de contato rígidas, devido à falta de estabilização e centração apropriadas. Foram descritos casos em que o uso de lentes de contato lenticular gelatinosa em pacientes com córnea plana resultou em sucesso óptico e cosmético ${ }^{11}$.

A medida do ângulo da câmara anterior no OD foi de $20,71^{\circ}$ e no OE $20,13^{\circ}$ o que é considerado de Grau 2 que, em certas circunstâncias, é susceptível de fechamento. Ângulos abertos, normais, são os de grau 3 ou 4 ( 30 a $\left.45^{\circ}\right)$, incapazes de fechamento ${ }^{12}$. Assim, esses pacientes devem ser acompanhados com exames periódicos com medida da pressão intra- ocular, para se detectar a presença de glaucoma mesmo se o ângulo da câmara anterior for aberto.

\section{SUMMARY}

Purpose: To report two cases of bilateral cornea plana with high hypermetropia.

Case report: Two members of the same family showed se-vere corneal flattening, limbal "scleralization". The sha-lowness of the anterior chamber, deep stromal corneal opacities and upper lid with ptotic appearance besides the familial distribuition are supposed to agree with the documented description of the recessive variety of cornea plana.

Discussion: The management of the cornea plana is discussed.

Keywords: Cornea plana; Sclerocornea; Hypermetropia; Congenital corneal anomaly.

\section{REFERÊNCIAS BIBLIOGRÁFICAS}

1. Waizenegger UR, KohnenT, Weidle EG, Schütte E. Kongenitale familiäre Cornea plana mit Ptosis, peripherer Sklerokornea und Bindehaut-Xerose. Klin Monastsbl Augenheilkd 1995;206:111-6.

2. Duke Elder S. In: Abnormalities in the curvature of the cornea - Cornea plana. In: Duke Elder S, ed. System of Ophthalmology, vol. 3, part 2, St Louis: Mosby 1976:505-8.

3. Belfort Junior R, Kara- José N. Anomalias Congênitas da Córnea. In: Córnea Clínica - Cirúrgica. São Paulo: Roca, 1996;35:389-94.

4. Smolin G. Congenital Anomalies of the Cornea and Conjunctiva - Abnormalities of Curvature.1994;17:539-53.

5. Krachmer, Mannis, Holland, Palay In: Developmental Corneal Anomalies of Size and Shape - Sclerocornea (Cornea Plana), 1998;76(1):2-3.

6. Tahvanainen E, Forsius H, Kolehmainen J, Damsten M, Fellman J, de la Chapelle. The genetics of cornea plana congenita. J Med Genet 1996 Feb; 33(2):116-9.

7. Sigler-Villanueva A, Cano MJM, Bravo RR, Córnea plana congénita. Rev Cubana Oftalmol 1997;10:1-2.

8. Online Mendelian Inheritance in Man ${ }^{\mathrm{TM}}$. Center for Medical Genetics, Johns Hopkins University (Baltimore, MD) and National Center for Biotechnology Informations, National Library of Medicine (Bethesda, MD), 1998.

9. Cameron JD, Perry HD - Congenital Abnormalities of the Cornea In: Duane's Ophthalmology on CD-ROM. Philadelphia: JB Lippincott, 1995;3:9.

10. Woods AC. The adjustment to aphakia. Am J Ophthalmol 1952;35:118-22.

11. Dada VK, Verma LK, Sachdev MS. Comprehensive visual and cosmetic rehabilitation of cornea plana. Cornea 1998;7(2):102-4.

12. Lichter PR. Gonioscopy. In: Duane's Ophthalmology on CD-Rom. Philadelphia. JB Lippincott Company, 1995;3:44

\section{Novidades na Internet!!!}

Agora no site CBO você tem disponível todas as informações na íntegra dos

$$
\text { Arquivos Brasileiros de Oftalmologia }
$$

http: //www. cbo.com.br/abo 